\title{
Techno-economical and energy analysis of sunflower oil biodiesel synthesis assisted with waste ginger leaves derived catalysts
}

\author{
Monnie John ${ }^{\mathrm{a}}$, Mohammad Omar Abdullah ${ }^{\mathrm{a}, \mathrm{d},{ }^{*}, \text { Tan Yie Hua }}{ }^{\mathrm{b}}$, Cirilo Nolasco-Hipólito ${ }^{\mathrm{c}}$ \\ a Department of Chemical Engineering \& Energy Sustainability, Faculty of Engineering, Universiti Malaysia Sarawak (UNIMAS), 94300, Kota Samarahan, \\ Sarawak, Malaysia \\ ${ }^{\mathrm{b}}$ Department of Chemical Engineering, Faculty of Engineering and Science, Curtin University Malaysia, CDT 250, 98009, Miri, Sarawak, Malaysia \\ ${ }^{\mathrm{c}}$ Instituto of Biotechnology, Universidad Del Papaloapan, Circuito Central 200, Col. Parque Industrial, CP. 68301, Tuxtepec, Oaxaca, 68000, Mexico \\ d OSYIHM Farm, Balai Ringin, Serian, C/o OSYIHM Enterprise, Lot 8532, Muara Tabuan Land District, 93350, Kuching, Sarawak, Malaysia
}

\section{A R T I C L E I N F O}

\section{Article history:}

Received 25 August 2020

Received in revised form

1 December 2020

Accepted 23 December 2020

Available online 29 December 2020

\section{Keywords:}

Biodiesel

Heterogeneous catalyst

Ginger leaves

Sunflower oil

Renewable energy-yield ratio

Sustainable economy

\begin{abstract}
A B S T R A C T
The present study was carried out to investigate biodiesel production via transesterification of sunflower oil employing heterogeneous catalyst derived from indigenous ginger (Zingiber Officinale) leaves. It also aims to compare the techno-economy performance of the ginger-based catalysts in 3 different forms viz. calcinated (CGL), activated by $\mathrm{KOH}(\mathrm{KGL})$ and $\mathrm{NaOH}(\mathrm{NGL})$. The plant-based catalysts were characterised by Scanning electron microscopy (SEM), Brunauer-Emmett-Teller (BET) and Fourier transform infrared spectroscopy (FTIR). The parametric effects on the biodiesel production such as reaction time, methanol to oil ratio and catalyst loading were investigated. The experimental result shows that $1.6 \mathrm{wt} \%$ catalyst, 6:1 M ratio of alcohol to oil, $1 \mathrm{~h} 30 \mathrm{~min}$ of reaction time with a speed of $200 \mathrm{rpm}$ gave the best results. It was found that the KGL obtained highest biodiesel yield of $93.83 \%$ under optimum conditions. Subsequently, the specific energy and energy productivity of KGL catalyst was found to be $1.2728,26.1544 \mathrm{MJ} /$ $\mathrm{kg}$ and $0.0382 \mathrm{~kg} / \mathrm{MJ}$, respectively, per $1 \mathrm{~L}$ of biodiesel. Meanwhile, the renewable energy to nonrenewable energy ratio for CGL, KGL and NGL is found to be 3.17, 4.01 and 3.67, respectively. A higher sustainable renewable energy-yield ratio and overall economical profit cost ratio are preferable for the biodiesel production process.
\end{abstract}

() 2020 Elsevier Ltd. All rights reserved.

\section{Introduction}

Biodiesel consumption has increased tremendously over the years (2006-2018) [1]. Like conventional diesel, biodiesel can be used as an alternative fuel for diesel engines and diesel burners. It can also be used as an additive to reduce vehicle emissions [2]. Currently in practice, most of the operating biodiesel plants are processed in batch using homogenous catalyst. This technology faces few difficulties such as expensive downstream separation methods, catalyst inadequacy and non-renewable catalysts used. Thus, transesterification is one of the alternative methods of biodiesel production in which triglycerides viz. vegetable oils or animal fats is reacted with alcohol with a catalyst to enhance the conversion of triglyceride into fatty acids methyl ester (FAME) and

\footnotetext{
* Corresponding author. Department of Chemical Engineering \& Energy Sustainability, Faculty of Engineering, Universiti Malaysia Sarawak (UNIMAS), 94300, Kota Samarahan, Sarawak, Malaysia.

E-mail addresses: amomar@unimas.my, amomar13@gmail.com (M.O. Abdullah).
}

glycerol as a product [3]. Global biodiesel production in 2019 was around 44.8 million tons (MnT) represent $19 \%$ of the global oils and fats consumption. Strong correlations are observed between diesel prices and vegetable oils prices, up to $90 \%$ for rapeseed oil, $88 \%$ for soybean oil and $85 \%$ for sunflower oil, (Pilorgé, 2020) [4]. Sunflower is one of the World's largest of oil seed crop cultivated for oil production. From a chemical reaction perspective, sunflower oil from natural sources is the leading primary raw material beneficial to biodiesel production, as the pure triglycerides conversion to fatty acid methyl ester is not only high but also with relatively short reaction time advantage [5].

In general, as edible oils, vegetable-based oils were regarded as not quite feasible for biofuel production; however, with the global huge volume production of sunflower oil could fairly offset such notion. The continuous replenish of sunflower planation could also possibly contribute to energy sustainability potential. As pointed out recently by Pilorgé (2020) [4], the evolution of sunflower crop at global scale and over a long period is quite remarkable, going from $10 \mathrm{MnT}$ for 9.6 million ha in 1975 to $52 \mathrm{MnT}$ for 27 Mha in 